Yuqian Chen, Junwen Zhou, Libo Zhang, Jinhui Peng, Shiwei Li*, Shaohua Yin, Kun Yang and Yaping Lin

\title{
Microwave-assisted and regular leaching of germanium from the germanium-rich lignite ash
}

https://doi.org/10.1515/gps-2017-0137

Received September 5, 2017; accepted November 15, 2017; previously published online January 24, 2018

Abstract: Demand for germanium $(\mathrm{Ge})$ is rapidly growing in recent years in various fields including semiconductors, aerospace, and solar cells. However, the Ge resources are very limited in the world. Hence, in this work, microwave-assisted leaching and conventional leaching methods are employed for the leaching of Ge from the Ge-rich lignite ash (GA). The effects of leaching temperature, leaching time, initial acid concentration, oxidizing agent amount, and stirring speed on leaching of Ge were investigated and microwave-assisted and conventional methods of leaching were compared. Here, $\mathrm{HCl}$ solution is used as a leaching agent, and $\mathrm{MnO}_{2}$ is used as an oxidizing agent. From the results, the leaching rate of $\mathrm{Ge}$ was found to be $89.49 \%$ in the microwave-assisted method, and $83.62 \%$ in the conventional leaching method. The optimal conditions for microwave-assisted method include a leaching temperature of $65^{\circ} \mathrm{C}$, a leaching time of $90 \mathrm{~min}$, an oxidizing agent amount of $10 \mathrm{~g} / \mathrm{l}$, an initial acid concentration of $10 \mathrm{~mol} / \mathrm{l}$, and a stirring speed of $250 \mathrm{rpm}$. The leaching rate of Ge significantly improved in the microwave-assisted method as compared to the conventional method. Therefore, the microwave-assisted method is a suitable method for the leaching of Ge from the GA and is a novel way for the efficient utilization of Ge concentrate.

Keywords: germanium (Ge); leaching; microwave.

\footnotetext{
*Corresponding author: Shiwei Li, State Key Laboratory of Complex Nonferrous Metal Resources Clean Utilization, Kunming University of Science and Technology, Kunming, Yunnan 650093, P.R. China, e-mail: lishiweikmust@163.com; Yunnan Provincial Key Laboratory of Intensification Metallurgy, Kunming, Yunnan 650093, P.R. China; and Faculty of Metallurgical and Energy Engineering, Kunming University of Science and Technology, Kunming, Yunnan 650093, P.R. China Yuqian Chen, Junwen Zhou, Libo Zhang, Jinhui Peng, Shaohua Yin and Kun Yang: State Key Laboratory of Complex Nonferrous Metal Resources Clean Utilization, Kunming University of Science and Technology, Kunming, Yunnan 650093, P.R. China; Yunnan Provincial Key Laboratory of Intensification Metallurgy, Kunming, Yunnan 650093, P.R. China; and Faculty of Metallurgical and Energy Engineering, Kunming University of Science and Technology, Kunming, Yunnan 650093, P.R. China

Yaping Lin: Faculty of Adult Education, Kunming University of Science and Technology, Kunming, Yunnan 650093, P.R. China
}

\section{Introduction}

Germanium (Ge) is another most important semiconductor material other than silicon [1]. In addition to its use in the semiconductor industry, this rare bulk metal being a promising industrial material, is also widely used in the fields of aerospace technology, high-frequency electronics, optical fiber communication, infrared optics, thermal solar cell, chemical catalyst, biomedical sciences, etc. [2-9]. At present, the average growth rate of Ge worldwide remains at $2 \%-4 \%$ per annum [10]. With the gradual increase in the applications of $\mathrm{Ge}$, the current $\mathrm{Ge}$ production is far from meeting the demand; thus, research needs to be urgently carried out to enhance the leaching rate of Ge.

At present, hydrometallurgy has become an effective way for recycling secondary resources [11], and the main processes of traditional technology method of recovering Ge from the Ge-rich lignite ash (GA) are as follows: (1) sulfuric acid leaching of GA, (2) precipitate Ge by tannin, (3) chloridizing roasting, (4) chlorination distillation, and (5) hydrolysis. The chlorination distillation is the most important step [12]. The chlorination distillation method is mainly divided into three parts as follows: firstly, $\mathrm{Ge}$ and other mineral elements generated chlorides. Secondly, Ge chloride is separated from other chlorides based on the different boiling points. Finally, the Ge chloride is hydrolyzed to generate the purified $\mathrm{GeO}_{2}$. Nevertheless, there are many issues in the cross of chloride distillation, such as low leaching rate of $\mathrm{Ge}$, difficulty in gathering the steam of Ge chloride, and some safety problems.

In recent years, microwave is used as an ancillary equipment in hydrometallurgy during the mineral leaching process. Apparently, this application is becoming increasingly prevalent [13-16]. The microwave is an electromagnetic wave that features $0.3-300 \mathrm{GHz}$ frequency and $0.1-100 \mathrm{~cm}$ wavelength. Microwave can separate and extract the valuable elements from the mineral efficiently by transmitting energy what the chemical reaction requires to molecule/atom directly by dielectric loss in mineral internally; on account of the microwaveabsorbing characteristic, the valuable mineral and gangue are so different that the temperature of multiphase complex mineral stone system is inhomogeneous in the 
distribution on microcosmic, intensifying the dissociation of valuable mineral and gangue, forming a nonequilibrium reaction and conditions and promotes interface chemical reaction [15-17]. This technology exhibits the characteristics of homogeneous heating and selective heating, which lead to many exceptional advantages over conventional processing methods including both energy and cost saving, improved thermal diffusivity and mass diffusivity, faster processing and greater eco-friendliness, making microwave heating appropriate for applications in hydrometallurgy [18-22].

In this study, leaching of $\mathrm{Ge}$ from the GA using microwave-assisted leaching is presented. The effects of leaching temperature, leaching time, initial acid concentration, oxidizing agent amount, and stirring speed on leaching of Ge are studied and microwave-assisted and conventional leaching methods are compared.

\section{Materials and methods}

\subsection{Materials}

The GA sample used in this work was obtained from Yunnan Province in PR China. The element composition of GA detected using X-ray fluorescence (XRF) technique is shown in Table 1; it can be seen that the main elements in the GA include $\mathrm{Si}, \mathrm{Al}, \mathrm{S}, \mathrm{Ca}, \mathrm{Fe}, \mathrm{K}$ and $\mathrm{Ge}$, and the accurate content of Ge in GA analyzed with chemical methods is $9263.2 \mathrm{~g} / \mathrm{t}$. The phase compositions that were analyzed with X-ray diffraction (XRD) are displayed in Figure 1, and it can be observed that $\mathrm{GA}$ consists of $\mathrm{Al}_{2} \mathrm{O}_{3}, \mathrm{SiO}_{2}, \mathrm{CaSO}_{4}, \mathrm{Ca}\left(\mathrm{PO}_{3}\right)_{2}, \mathrm{KPO}_{3}$, and $\mathrm{GeO}_{2}$. The microstructure and element distribution of GA were observed using scanning electron microscopy-energy-dispersive X-ray spectroscopy (SEM-EDS) technique, as shown in Figure 2. It can be found that GA consisted of relatively smooth white particles with a size between $3 \mu \mathrm{m}$ and $150 \mu \mathrm{m}$ and amorphous powders with a size $<20 \mu \mathrm{m}$. Specially, the EDS analysis results of point A and point B indicate that the Ge exists in two different types of phases. The oxidizing agent used in this research was $\mathrm{MnO}_{2}$ (Tianjin Fengchuan Chemical Reagent technologies Co., Ltd.) in view of its industrial application in the future.

\subsection{Apparatus and procedure}

Microwave-assisted leaching experiments are carried out using the micro-assisted leaching equipment. The equipment assembled in the Key Laboratory of Unconventional Metallurgy in Kunming University of Science and Technology consisted of high-pressure toughened glass reactor, NJL2-8 microwave oven (supplied by Nanjing Jiequan Microwave Development Co., Ltd), DSX-120 digital stirring (supplied by Hangzhou instrument electric co., Ltd.), thermoelement (supplied by Dongtai Xinrui Instruments Co., Ltd.), Erlenmeyer flask, and SHB-III circulating water vacuum pump (supplied by Zhengzhou Great Wall instrument co., Ltd.). The output power of the microwave was automatically controlled by the temperature. The schematic diagram of the micro-assisted leaching experimental setup is shown in Figure 3.

$2.00 \mathrm{~kW}$ was chosen as the microwave power output in this work. The solution temperature was measured by a thermoelement, which is plugged inside the reaction vessel in the $0^{\circ} \mathrm{C}-120^{\circ} \mathrm{C}$ range. A lid covered the vessel to ensure a tight seal and was connected with the stirrer, thermoelement and breather pipe, which was used to guide Ge tetrachloride vapor to the condenser pipe. The output power of the microwave oven can be continuously adjusted from 0 to $2.5 \mathrm{~kW}$. When the solution temperature reaches the target temperature, the microwave-assisted leaching experiment begins. The SHB-III circulating water vacuum pump was opened to guide Ge tetrachloride vapor into condenser pipe and collect in conical flask after the leaching experiment was completed.

\subsection{Exploratory experiment}

Firstly, the glass reactor was loaded with $100 \mathrm{~g}$ of GA mixed with $\mathrm{HCl}$ and $\mathrm{MnO}_{2}$; then placed in the microwave oven and heated to a certain temperature. Secondly, the solution was heated to $95^{\circ} \mathrm{C}$ after the leaching reaction. Thirdly, the circulating water vacuum pump was started and Ge tetrachloride vapor was collected in an Erlenmeyer flask through a condenser pipe. Finally, on completion of the experiment, the lixivium and the leaching residue were separated and the concentration of Ge was estimated by chemical analysis.

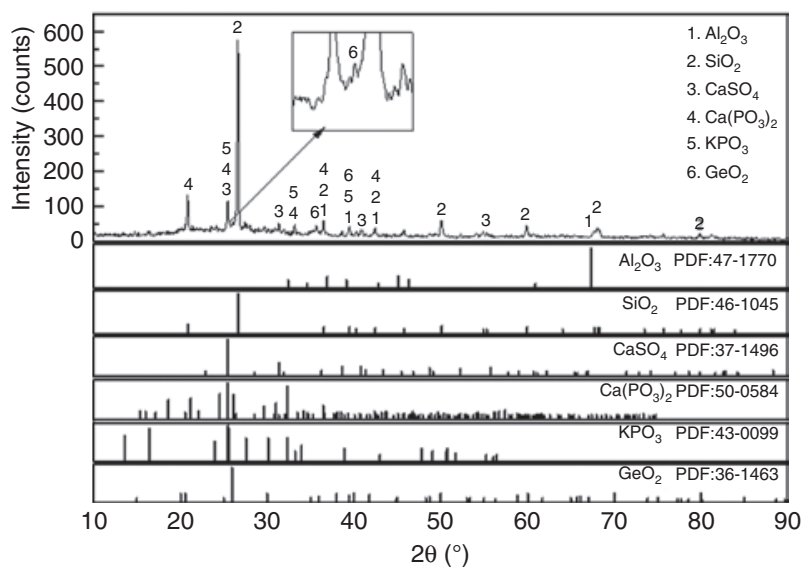

Figure 1: XRD pattern of Ge-rich lignite ash (GA).

Table 1: Major chemical composition of raw material (\%).

\begin{tabular}{lrrrrrrrrrrrrrr}
\hline Element & Si & Al & S & Ca & Fe & K & Ge & Zn & Mg & Na & As & Pb & W & P \\
\hline Content & 51.76 & 12.79 & 10.99 & 8.25 & 6.36 & 3.48 & 1.73 & 0.92 & 0.88 & 0.71 & 0.66 & 0.42 & 0.23 & 0.20 \\
\hline
\end{tabular}




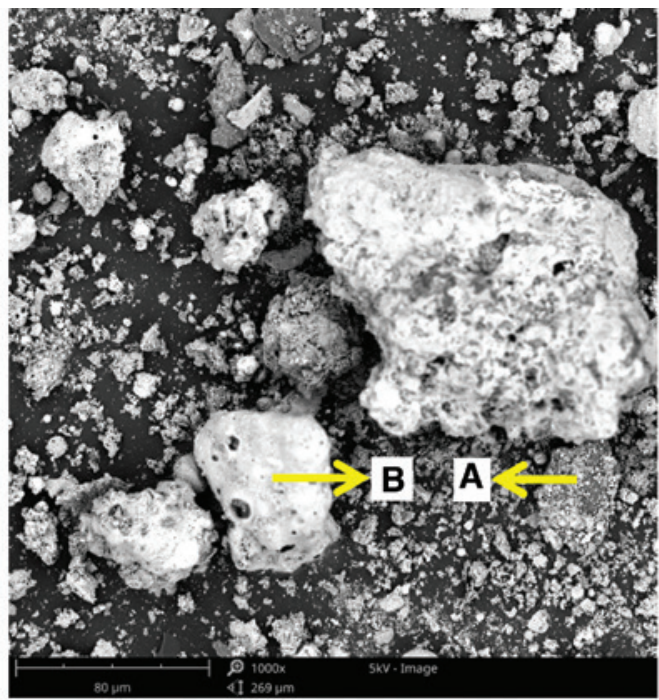

A

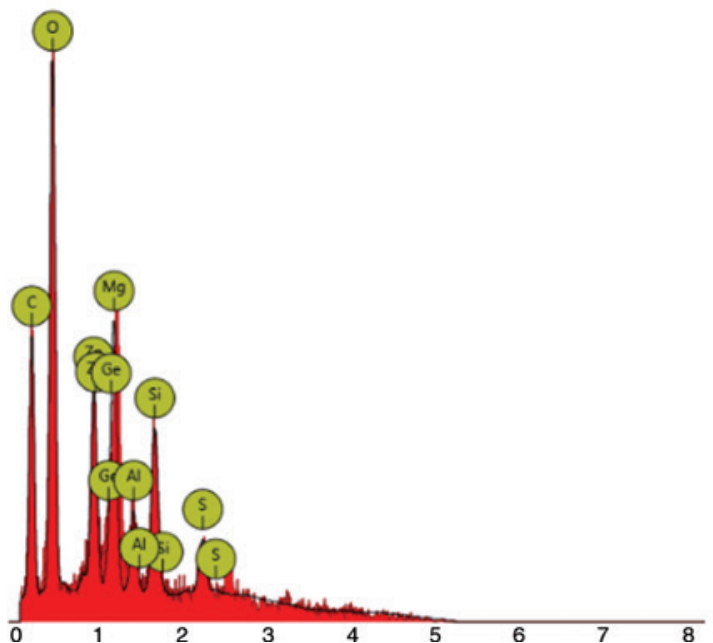

B

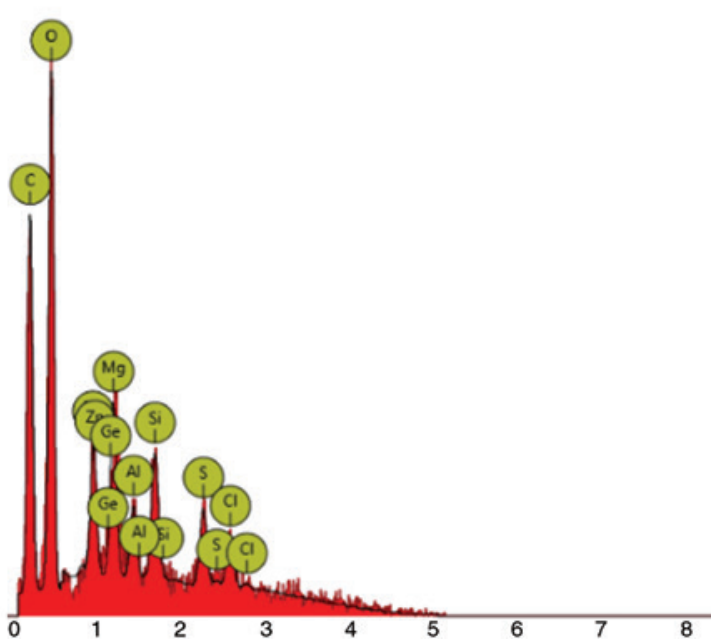

Figure 2: SEM-EDS analysis of GA. (A) EDS spectrum of point A, and (B) EDS spectrum of point $B$.

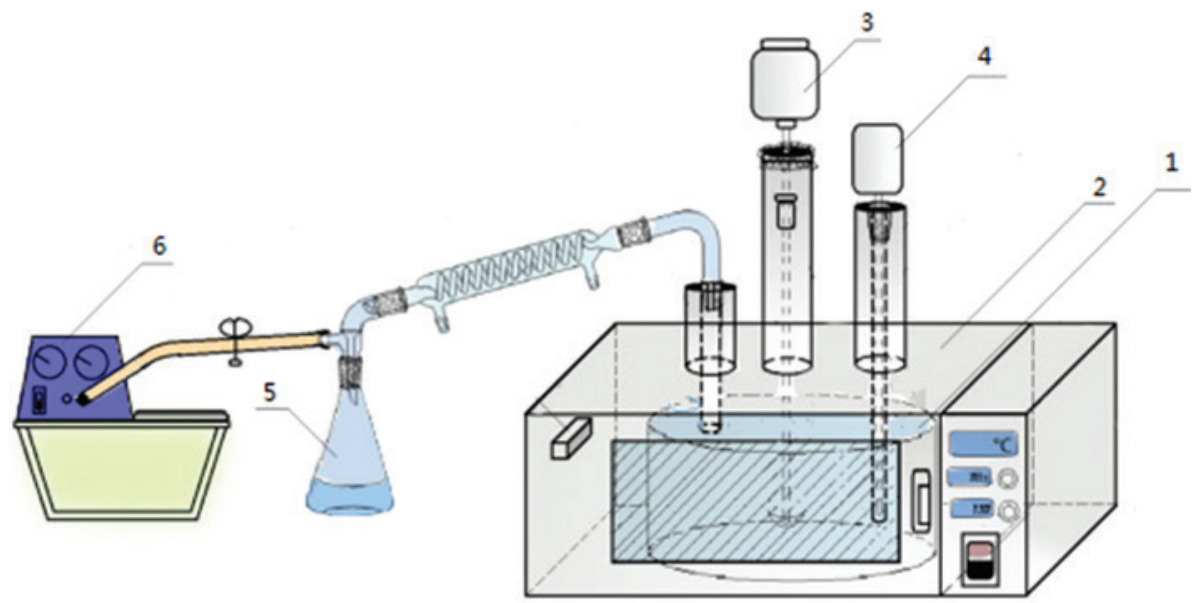

Figure 3: Microwave-assisted leaching equipment diagram: (1) high pressure toughened glass reactor, (2) NJL2-8 microwave oven, (3) DSX-120 digital stirrer, (4) thermoelement, (5) conical flask, and (6) SHB-III circulating water vacuum pump. 


\subsection{Calculation method of leaching rate of $\mathrm{Ge}$}

The leaching rate is calculated by following equation:

$$
X=\frac{m_{0} \cdot C_{0}-m_{1} \cdot C_{1}}{m_{0} \cdot C_{0}} \times 100 \%
$$

where $X$ is the leaching rate of Ge, $\% ; m_{0}$ is the initial mass of GA in leaching experiment, $\mathrm{g} ; C_{0}$ is the content of Ge in raw material, $\mathrm{g} / \mathrm{t}$; $m_{1}$ is the mass of leached residue, g; and $C_{1}$ is the content of Ge in the leached residue, $\mathrm{g} / \mathrm{t}$.

\section{Results and discussion}

$\mathrm{Ge}$ is the target element of this research. In order to explore the best conditions for leaching Ge from GA and to discuss the effect of the present method by using a microwave, the optimum leaching conditions are obtained by investigating the effect of leaching time, leaching temperature, concentration of $\mathrm{HCl}$, and stirring speed. After some grouping experiments, 4:1 is set as the liquid-solid ratio in all experiments and $2 \mathrm{~kW}$ microwave power was adopted in this research.

\subsection{Effect of leaching temperature on leaching rate of $\mathrm{Ge}$}

$\mathrm{GeO}_{2}$ is reduced to metallic $\mathrm{Ge}$ in the process of microwave leaching of $\mathrm{GA}$, and then Ge tetrachloride is evaporated into a gaseous phase and condensed on the low-temperature zone. The reaction between $\mathrm{GeO}_{2}$ and $\mathrm{HCl}$, and the standard Gibbs free energy $\left(\Delta G^{\circ}\right)$ are listed in Eq. (2) [23]:

$$
\mathrm{GeO}_{2}+4 \mathrm{HCl} \leftrightharpoons \mathrm{GeCl}_{4}+\mathrm{H}_{2} \mathrm{O} \quad \Delta \mathrm{G}^{o}=-41.09 \mathrm{~kJ} / \mathrm{mol}
$$

The experiments were conducted in the temperature range from $40^{\circ} \mathrm{C}$ to $70^{\circ} \mathrm{C}$; the concentration of $\mathrm{HCl}$ was $10 \mathrm{~mol} / \mathrm{l}$, the leaching time was $90 \mathrm{~min}$ while the stirring speed was $250 \mathrm{rpm}$. The relationship between the recovery of $\mathrm{Ge}$ and the reaction temperature is shown in Figure 4. The leaching rate increases with a temperature between $40^{\circ} \mathrm{C}$ and $65^{\circ} \mathrm{C}$ by the microwave-assisted method and it is similar from $40^{\circ} \mathrm{C}$ to $55^{\circ} \mathrm{C}$ by the regular method. The microwave treatment presented a higher leaching rate of $\mathrm{Ge}$ than that of the regular method $(89.01 \%$ and $84.35 \%$, respectively) when the temperature was $65^{\circ} \mathrm{C}$.

However, if the temperature is higher than $65^{\circ} \mathrm{C}$, the leaching rate decreases, which may be due to the increased hydrolysis. When the system temperature is higher than

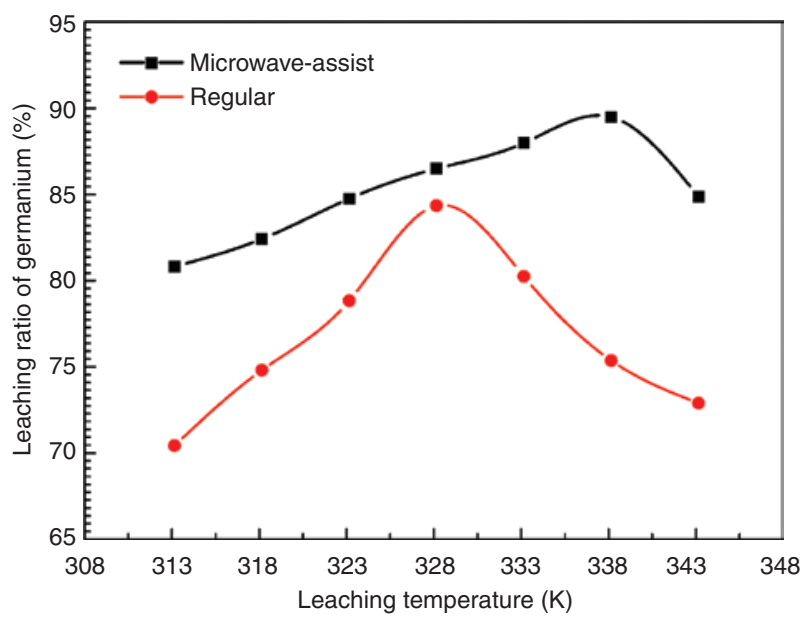

Figure 4: Effect of leaching temperature on leaching rate of Ge.

$65^{\circ} \mathrm{C}$, the $\mathrm{HCl}$ will decrease rapidly; parts of the $\mathrm{HCl}$ will evaporate and parts of the $\mathrm{HCl}$ will involve in fast reaction with other element at high temperature. The hydrolysis reaction is listed in Eq. (3):

$$
\mathrm{GeCl}_{4}+2 \mathrm{H}_{2} \mathrm{O} \leftrightharpoons \mathrm{GeO}_{2}+4 \mathrm{HCl}
$$

The generated $\mathrm{GeO}_{2}$ belongs to the residue, which will decrease the leaching rate of Ge. Similarly, the heating time of the regular method is longer than that of the microwave method; the higher the target temperature, the longer it takes. As a result, the hydrochloric acid concentrations are reduced, and Ge tetrachloride hydrolysis is reduced seriously.

\subsection{Effect of leaching time on leaching rate of $\mathrm{Ge}$}

The effect of time on Ge leaching with microwave treatment and regular method was investigated from 30 to $150 \mathrm{~min}$. These experiments were conducted at $65^{\circ} \mathrm{C}-55^{\circ} \mathrm{C}$ microwave-assisted/regular, and the stirring speed was $250 \mathrm{rpm}$ and the concentration of $\mathrm{HCl}$ was $10 \mathrm{~mol} / \mathrm{l}$. The relationship between recovery ratio of $\mathrm{Ge}$ and time is shown in Figure 5. The leaching quality increases significantly from 30 to 90 min due to the crystal structure destroyed by microwave selectivity heating and emerges with more pores that increased the contact rate between $\mathrm{Ge}$ and $\mathrm{HCl}$, and the similar phenomenon appears from 30 to $90 \mathrm{~min}$ when operated with regular method. However, in both methods, the leaching quality decreases greatly after $90 \mathrm{~min}$.

During the leaching process, some component including $\mathrm{GeO}_{2}$ will react with $\mathrm{HCl}$; moreover, $\mathrm{HCl}$ will volatilize at a relatively high temperature. As a result, the 


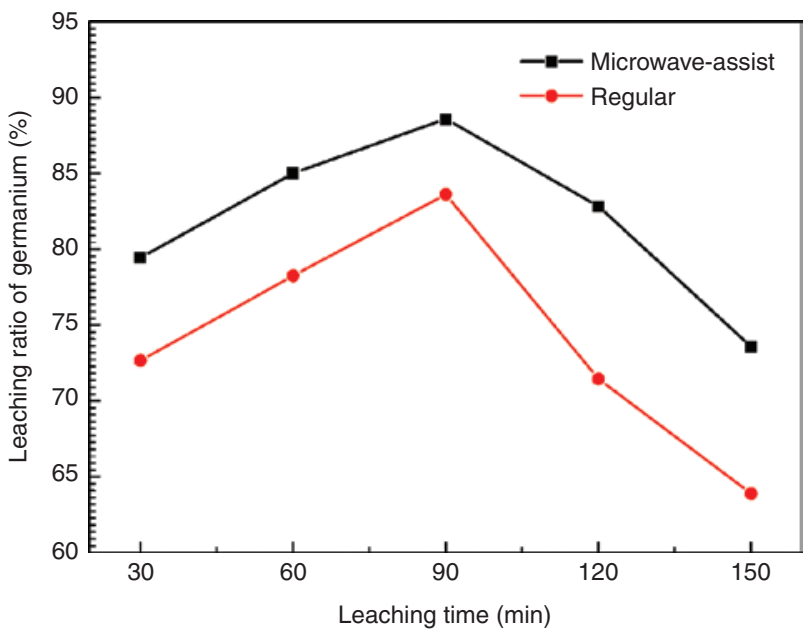

Figure 5: Effect of leaching time on leaching rate of Ge.

concentration of $\mathrm{HCl}$ will decrease. With the increase of chlorides and the decrease of the concentration of $\mathrm{HCl}$, $\mathrm{GeCl}_{4}$ is hydrolyzed to $\mathrm{GeO}_{2}$, which will precipitate in the final slag.

Figure 5 shows that the optimal leaching rate of Ge with 90 min of microwave treatment is $88.59 \%$, whereas the optimal leaching rate with $90 \mathrm{~min}$ of regular leaching is $83.62 \%$. Water bath heating from $25^{\circ} \mathrm{C}$ to $55^{\circ} \mathrm{C}$ is needed for $20 \mathrm{~min}$, and $2 \mathrm{~kW}$ microwave heating for only 2-3 min. It indicates that the heating time is reduced by as much as $90 \%$ and the leaching rate of $\mathrm{Ge}$ is enhanced by microwave leaching. The experimental result shows that leaching rate of $\mathrm{Ge}$ is enhanced and the experimental period distinctly shortened with the microwave method. It may be mainly attributed to the microwave selective heating and polarization effect, which destroy the crystal structure and emerge porously or react with additives to update the response interface, thus inducing increase in the contact rate between $\mathrm{Ge}$ and $\mathrm{HCl}$ [24-26], and the microwave absorption of water is extremely strong; the polar vibration of water molecules enhances the mass transfer, improves the kinetics of leaching, reduces the mass transfer resistance of $\mathrm{HCl}$ and products to enhance the effect $[27,28]$.

\subsection{Effect of initial acid concentration on leaching rate of $\mathrm{Ge}$}

As the $\mathrm{HCl}$ solution is adopted as the leaching system, so the initial acidity is a vital factor in the process of Ge leaching. Figure 6 shows that the optimal concentration of $\mathrm{HCl}$ is $10 \mathrm{~mol} / \mathrm{l}$, and the leaching rate of Ge with microwave treatment is $4.33 \%$ higher than that with regular method (86.75\% and $82.42 \%$, respectively).

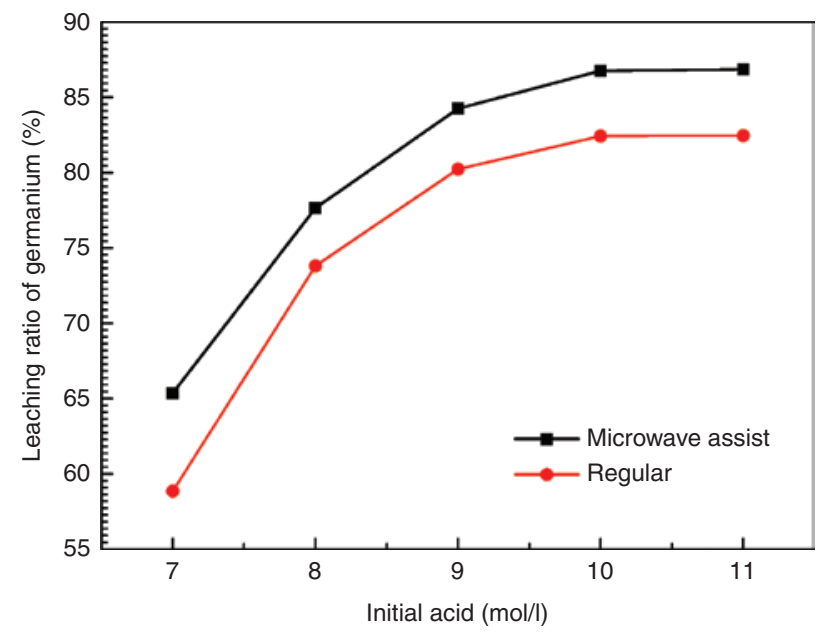

Figure 6: Effect of initial acid concentration on leaching rate of Ge.

The leaching rate of $\mathrm{Ge}(84.24 \%)$ in $9 \mathrm{~mol} / \mathrm{l} \mathrm{HCl}$ with microwave treatment is even higher than that $(82.42 \%)$ in the optimum $10 \mathrm{~mol} / \mathrm{l} \mathrm{HCl}$ with the conventional method. Some analyses conducted are as follows: firstly, the higher the acidity of the reactants the more favorable the leaching response balance moves to the resultant. In addition, an increase in the concentration of chloride ion as a coordination agent is beneficial to produce the coordination compound with chloride ion, which increases the leaching rate of $\mathrm{Ge}$. In fact, the $\mathrm{GeCl}_{4}$ is soluble in dilute $\mathrm{HCl}$; with the increase in $\mathrm{HCl}$ concentration, its solubility increases. When the concentration of hydrochloric acid is up to $6-7 \mathrm{~mol} / \mathrm{l}$, $\mathrm{GeCl}_{4}$ has the greatest solubility. If the initial concentration of $\mathrm{HCl}$ is too low, it will cause an incomplete reaction of $\mathrm{Ge}$ in the raw material; the resulting $\mathrm{GeCl}_{4}$ is easily hydrolyzed to produce the $\mathrm{GeO}_{2}$ precipitation [23], thereby reducing the leaching rate of $\mathrm{Ge}$.

\subsection{Effect of oxidizing agent amount on leaching rate of $\mathrm{Ge}$}

Due to some elements of the raw material existing in an elementary substance, there is a strong reducibility, making the oxidation-reduction potential of Ge higher, so the leaching process must have enough oxidants to oxidize these elementary substances [29].

$\mathrm{Cl}_{2}$ gas is usually adopted as the oxidizing agent in the industries, but there are some potential safety hazards while using $\mathrm{Cl}_{2}$ during the operation. In the experiments, the solid-state $\mathrm{MnO}_{2}$ is chosen to replace $\mathrm{Cl}_{2}$ gas. The amount of oxidizing agent is very important to oxide metals, which are in a state of incomplete oxidation during the leaching stage. 


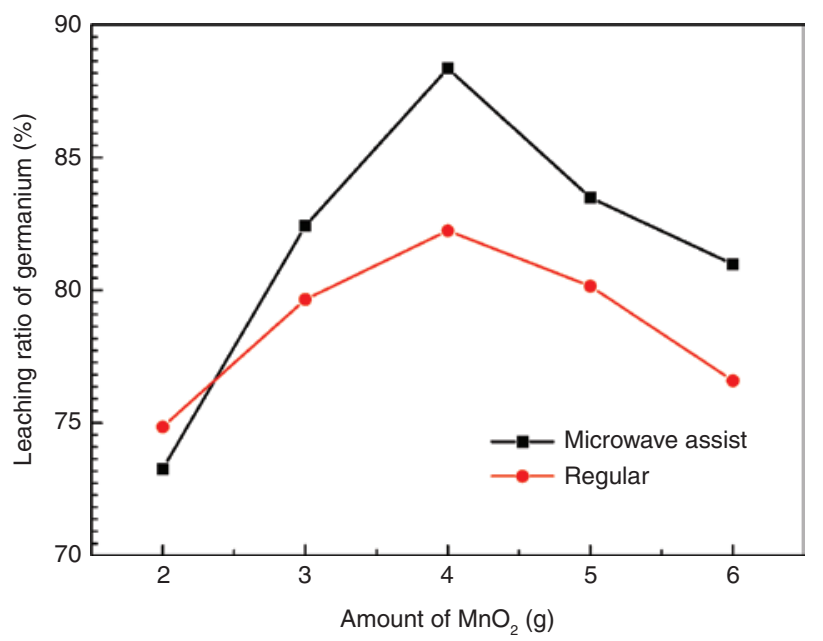

Figure 7: Effect of oxidizing agent amount on leaching rate of Ge.

The effects of the amount of oxidizing agent on the leaching behavior of Ge are shown in Figure 7. It can be found that Ge leaching can be enhanced when the addition of oxidizing agent reaches $4 \mathrm{~g}$. At the optimal leaching condition of this section, the leaching rate of Ge by microwave treatment is $6.12 \%$ higher than the regular method ( $88.36 \%$ and $82.24 \%$, respectively). The leaching rate of Ge reduces with excessive oxidant due to the concentration of $\mathrm{HCl}$ changing with the adding of $\mathrm{MnO}_{2}$. The chemical reaction given as follows will occur:

$$
4 \mathrm{HCl}+\mathrm{MnO}_{2} \stackrel{\Delta}{\longrightarrow} \mathrm{MnCl}_{2}+\mathrm{Cl}_{2} \uparrow+2 \mathrm{H}_{2} \mathrm{O}
$$

It can be observed that $\mathrm{Cl}_{2}$ produced in this reaction, works as an oxidant, which influences the $\mathrm{GeCl}_{4}$ solubility.

\subsection{Effect of stirring speed on leaching rate of $\mathrm{Ge}$}

To observe the effect of stirring speed on the leaching rate, experiments were carried out using five different stirring speeds in the range of 200-400 rpm. These experiments were conducted at $65^{\circ} \mathrm{C} / 55^{\circ} \mathrm{C}$ (microwave-assist/regular), leaching time was $90 \mathrm{~min}$ and the concentration of $\mathrm{HCl}$ was $10 \mathrm{~mol} / \mathrm{l}$. The experimental results that are given in Figure 8 , show that both methods of the leaching quality increase inconspicuously from $200 \mathrm{rpm}$ to $250 \mathrm{rpm}$, and leaching rate has slight fluctuation from 250 to $400 \mathrm{rpm}$; the leaching rate is nearly independent of the stirring speed. The $250 \mathrm{rpm}$ chosen in this experiment is to prevent solid and liquid-state admixture to the container wall due to high stirring speed.

The experimental parameters are gradually optimized, and the optimal conditions of microwave-assisted

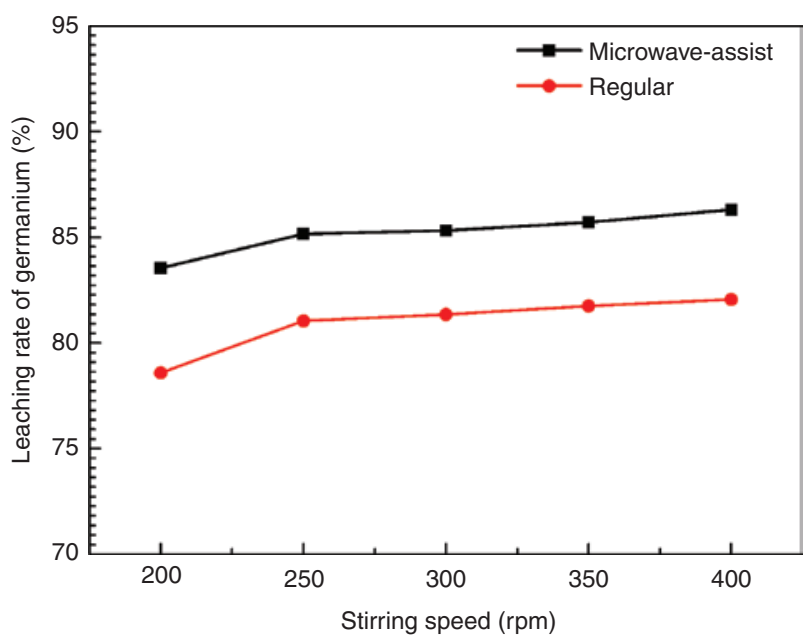

Figure 8: Effect of stirring speed on leaching rate of $\mathrm{Ge}$.

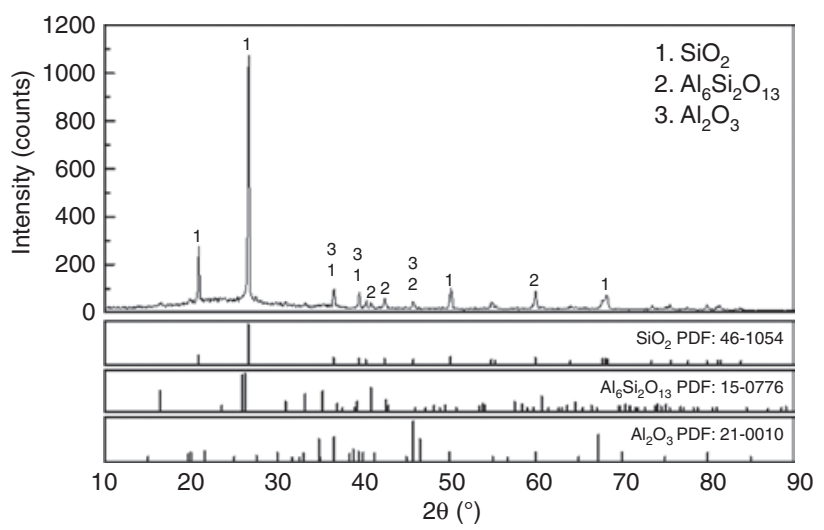

Figure 9: XRD pattern of the residual slag after microwave-assist leaching process.

leaching were as follows: leaching temperature of $65^{\circ} \mathrm{C}$, leaching time of $90 \mathrm{~min}$, oxidizing agent amount of $10 \mathrm{~g} / \mathrm{l}$, initial acid concentration of $10 \mathrm{~mol} / \mathrm{l}$, and stirring speed of $250 \mathrm{rpm}$. The maximum leaching ratio is $89.49 \%$, which is significantly higher than that of conventional leaching method.

\subsection{Characteristics of the residual slag after leaching process}

The phase composition of leaching residue (leaching conditions: temperature $65^{\circ} \mathrm{C}$, leaching time $90 \mathrm{~min}, \mathrm{HCl}$ concentration $10 \mathrm{~mol} / \mathrm{l}$, stirring speed $250 \mathrm{rpm}$ ) is shown in Figure 9, and it can be found that the residual slag consists of $\mathrm{SiO}_{2}, \mathrm{Al}_{6} \mathrm{Si}_{2} \mathrm{O}_{13}$, and $\mathrm{Al}_{2} \mathrm{O}_{3}$. The other phases have reacted with $\mathrm{HCl}$ during leaching process. The residual $\mathrm{GeO}_{2}$ in the reaching residue cannot be detected by XRD due to its very low content. 


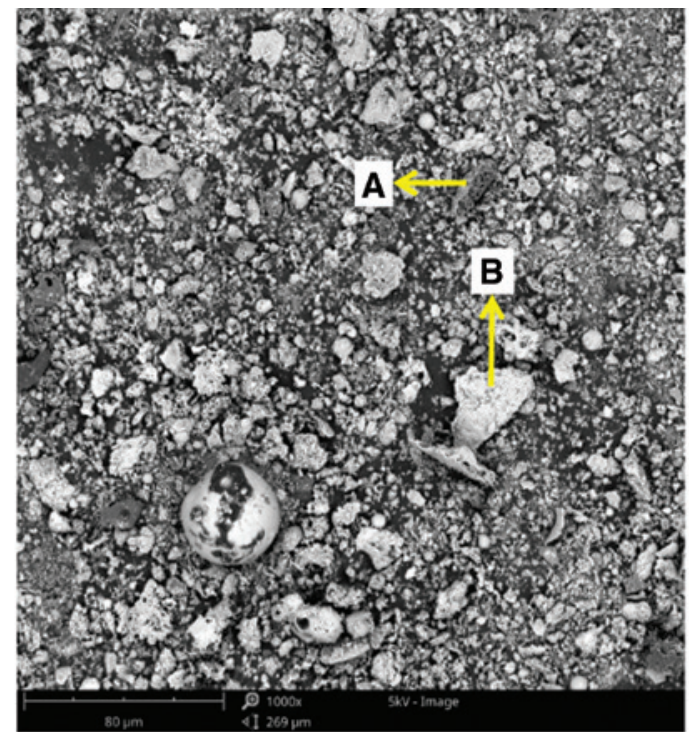

A

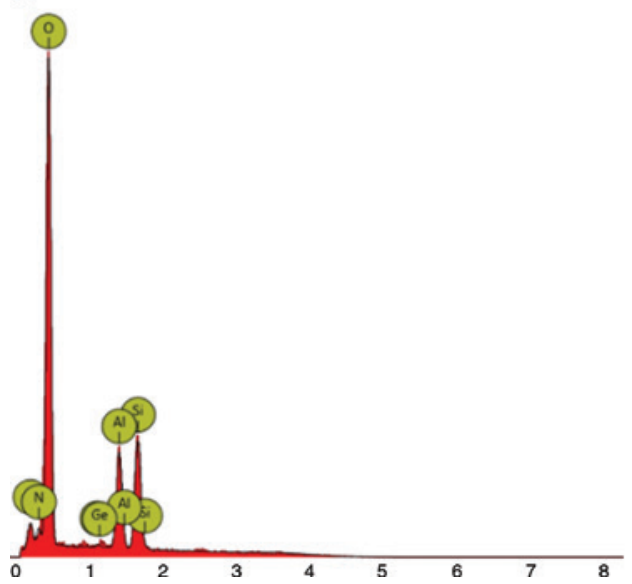

\section{B}

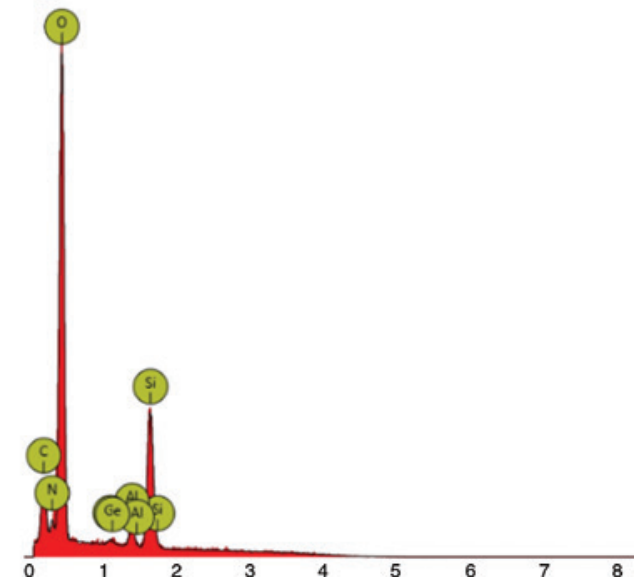

Figure 10: SEM-EDS analysis of the residual slag after microwave-assisted leaching process. (A) EDS spectrum of point A, and (B) EDS spectrum of point $B$.

The microstructure and element distribution of leaching residue were observed with SEM-EDS, as shown in Figure 10, and it can be found that the microstructure of leaching residue is different from that of GA. The leaching residue mainly consists of amorphous powders with the size $<30 \mu \mathrm{m}$. The peak strength of $\mathrm{Ge}$ is weak, which indicates that the content of $\mathrm{Ge}$ in the leaching residue is low, as shown in the EDS spectra of point $\mathrm{A}$ and point $\mathrm{B}$. The microwave absorbing ability and thermal conductivity coefficient of various crystalline phases in the GA are different, and the temperature differences between different phases generated in the microwave-assisted leaching process will result in the local crushing stress and tension stress [30]. The formation of internal tiny cracks of slag particles increases the effective reaction interface area and therefore promotes the rate of leaching reaction [31].

\subsection{Leaching behavior of the impurity ions from the GA}

The leaching behaviors of the impurity ions such as $\mathrm{Al}^{3+}$, $\mathrm{Ca}^{2+}, \mathrm{Fe}^{3+}, \mathrm{K}^{+}$, etc. in the microwave-assisted leaching process were analyzed with XRF, and the element composition of the leaching residue (leaching conditions: temperature $65^{\circ} \mathrm{C}$, leaching time $90 \mathrm{~min}, \mathrm{HCl}$ concentration $10 \mathrm{~mol} / \mathrm{l}$, stirring speed $250 \mathrm{rpm}$ ) is shown in Table 2. It 
Table 2: Element composition of the reaching residue (\%).

\begin{tabular}{rrrrrrrrrrrrrrrrr}
\hline Element & Si & Al & S & Ca & Fe & K & Ge & Zn & Mg & Na & As & Pb & W & P \\
\hline Content & 76.90 & 10.89 & 0.92 & 1.46 & 2.66 & 3.09 & 0.59 & 0.17 & 0.60 & 0.25 & 0.05 & 0.05 & 0.17 & 0.05 \\
\hline
\end{tabular}

can be deduced that the $\mathrm{S}, \mathrm{Ca}, \mathrm{Fe}, \mathrm{Zn}$ and $\mathrm{Pb}$-containing phases are extensively dissolved. In contrast, the $\mathrm{Si}, \mathrm{Al}$ and $\mathrm{K}$-containing phases are not soluble in $\mathrm{HCl}$ system.

\section{Conclusions}

In this study, the recovery of Ge from GA using microwaveassisted leaching was investigated. Some conclusions are arrived at as follows:

1. Comparison of the leaching rate of normal leaching method with that of the microwave-assisted leaching is significantly improved. The leaching ratio is $89.49 \%$ under the optimized technological parameters as follows: leaching temperature of $65^{\circ} \mathrm{C}$, leaching time of $90 \mathrm{~min}$, oxidizing agent amount of $10 \mathrm{~g} / \mathrm{l}$, initial acid concentration of $10 \mathrm{~mol} / \mathrm{l}$ and stirring speed of $250 \mathrm{rpm}$.

2. The main reason for the low leaching rate of $\mathrm{Ge}$ is the hydrolysis of $\mathrm{GeCl}_{4}$. The main factors that affect hydrolysis are the concentration of $\mathrm{HCl}$ and leaching time, $\mathrm{GeCl}_{4}$ hydrolysis seriously under the condition that the concentration of $\mathrm{HCl}$ is lower than $7 \mathrm{~mol} / \mathrm{l}$ and leaching time is too long, resulting in low $\mathrm{Ge}$ leaching rate.

3. The microwave-assisted method is a suitable method for the leaching of $\mathrm{Ge}$ from the Ge-rich lignite ash due to the extremely strong microwave absorption of water and the microwave internal heating and rapid heating.

Acknowledgments: The authors thank the National Natural Science Foundation of China (Funder id: 10.13039/501100001809, 51604135) and Kunming University of Science and Technology for their support.

\section{References}

[1] Nie H, Chen B. Chin. Integrated Circuit 2010, 1, 71-78.

[2] Meng LQ, Fei YC. ACTC Armamentarll 2004, 25, 78-81.

[3] Chu NL. Chin. J. Rare Metals 1998, 22, 369-374.
[4] Feng DS, Su XP, Min ZD, Yin SP. Chin. J. Rare Metals 2006, 30, 692-694.

[5] Wang SA, Feng XP, Yin SP. Chin. J. Rare Metals 2007, 31, 511-514.

[6] Feng DS, Li N, Su XP, Yang H, Min ZD. Chin. J. Rare Metals 2008, 32, 34-37.

[7] Li MM, Su XP, Feng DS, Wang XW, Zuo JL. Chin. J. Rare Metals $2010,17,78-82$.

[8] Jiang W. J. Guangdong Univ. Petrochem. Technol. 2000, 3, 629-631.

[9] Huang WZ. Shanghai Nonferrous Metals 1993, 5, 59-60.

[10] Zhang HC, Wang JP, Wang JG, Zhang ZB, Lu J. Resour. Indus. 2016, 18, 92-97.

[11] Kim E, Horckmans L, Spooren J, Vrancken KC, Quaghebeur M, Broos K. Hydrometallurgy 2017, 169, 372-381.

[12] Zhang LB, Guo WQ, Peng JH, Li J, Lin G, Yu X. Ultrason. Sonochem. 2016, 31, 143-149.

[13] Al-Harahsheh M, Kingman SW. Hydrometallurgy 2004, 73, 189-203.

[14] Ford JD, Pei DCT. J. Microwave Power 1967, 2, 61-62.

[15] Xue J, Wang W, Wang QH. Trans. Nonferrous Met. Soc. Chin. $2008,62,75-79$.

[16] Liu SZ, Bai Y, Cheng YM, Zhong W. Hydrometallurgy Chin. 2011, 30, 91-94.

[17] Ai LQ, Zhang YL, Zhu YH, Zhang XM. Energy Metall. Indus. 2013, $32,42-44$.

[18] Lin G, Liu CH, Zhang LB, Hu T, Peng JH, Li J, Wang SX. J. Hazard. Mater. 2017, 330, 36-45.

[19] Lin G, Zhang LB, Peng JH, Hu T, Li Y. Appl. Therm. Eng. 2017, 117, 668-674.

[20] Wen T, Zhao YL, Xiao QH, Ma QL, Kang SC, Li HQ, Song SX. Results Phys. 2017, 7, 2594-2600.

[21] Tong ZB, Ma GQ, Zhang X, Cai YS. Minerals 2017, 7, 119-132.

[22] Turan MD, Sari ZA, Miller JD. Trans. Nonferrous Metals Soc. Chin. 2017, 27, 1404-1410.

[23] Lei T, Zhang YL, Wang SL. Extraction Method of Germanium. Metallurgical Industry Press: Beijing, 2008, 106-117.

[24] Jian J, Xia HY, Peng JH, Zhang LB, Lu SD, Dai HK, Zhang BQ, Liu BH, Shi YF. J. Kunming Univ. Sci. Technol. (Natural Science Edition), 2012, 37, 72-77.

[25] Huang JH, Rowson NA. Rare Met. 2000, 19, 161-171.

[26] Ding WA. Rare Met. 1997, 16, 153-155.

[27] Xiao ZF. GuangDong: South Chin. Univ. Technol. 2009, 1-16.

[28] Wang Y, Sun HT, Wang BH, Zhang D. Liaoning Chem. Indus. 2006, 35, 167-169.

[29] Wang XN. HuNan: Central South Univ. 2012, 40-45.

[30] Chen Y, Yoshikawa NB, Taniguchi SJ. ISIJ Int. 2005, 45, 1232-1237.

[31] Zhang X, Ma GJ, Tong ZB, Xue Z. J. Min. Metall. Sect. B 2017, 53, 139-146. 